\title{
A NEW SCENOPINIDAE (DIPTERA) FROM BERMUDA ${ }^{1}$
}

\section{By L. P. KeLseY ${ }^{2}$}

While examining the Scenopinidae in the collection of the Museum of Comparative Zoology, I noted a specimen collected in Bermuda. As there are relatively few records of Scenopinids from islands this specimen was retained for more detailed study and was found to be a new species in the Velutinus Group as evidenced by the narrowed bursal cavity. This species would key to Scenopinus nubilipes Say in the keys to the Nearctic females (Kelsey, r 1969) but may be separated from that species on the basis of the bursal cavity, conformation of the 8th sternum and the markings on the frons.

In the accompanying illustrations scale marks equal one half millimeter, the shorter applies to the head and wings, the longer to the terminalia.
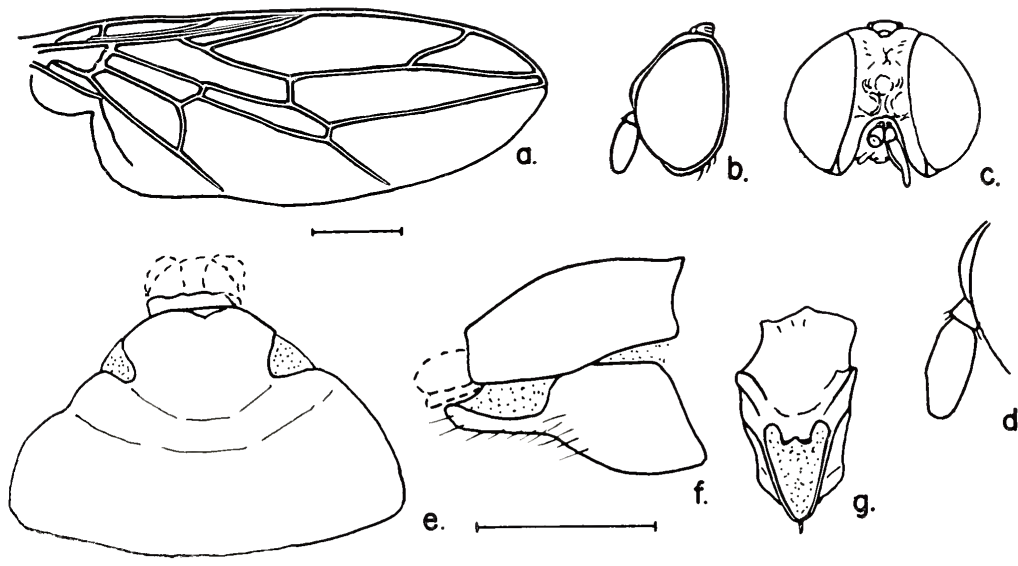

Figure 1. Scenopinus bermudaensis n. sp. + ; a. wing; b. c. lateral and frontal aspects of head; d. enlarged detail of antennae; e. f. lateral and ventral aspects of 8 th and 9th segments, missing portions outlined by dashed lines; g. roof of bursal cavity.

${ }^{1}$ Published as Miscellaneous Publication No. 633 with the approval of the Director of the Delaware Agricultural Experiment Station. Publication No. 408 of the Department of Entomology and Applied Ecology.

${ }^{2}$ Associate Professor, Department of Entomology and Applied Ecology, University of Delaware, Newark, Delaware, 19711.

Manuscript received by the editor May 3, 1971. 


\section{Scenopinus bermudaensis n. sp.}

Figure I

Holotype: (female) - Bermuda, May I 5, I 909, F. M. Jones. Coll.; Museum of Comparative Zoology, Cambridge, Mass. Type no. 3200 .

Length body: $4.0 \mathrm{~mm}$., wing $3.2 \mathrm{~mm}$.

\section{Female}

Head red-brown; eyes brown with a very narrow postocular ridge; frons broad, rugose, swollen on lower portion, divided by a shallow median groove ending in a shallow depression on lower fourth, frons elevated above eye margins; ocellar tubercle red-brown, distinct, cut off; ocelli orange; mouthparts yellow-brown, well developed; palpi red-brown; oral cavity bordered by silvery pubescence that extends to bulge on lower frons; antennae with first segment red-brown, short; second segment orange-brown; third segment red-brown, pubescent, about twice as long as broad; see figure for details.

Thorax with dorsum red-brown, rugose; humeral and supra-alar calli orange-brown; pleural areas red-brown; wings brown fumose, veins brown; halter stem red-brown, knob red-brown; legs with femora and tibiae red-brown, tarsi orange-brown.

Abdomen red-brown; tip of 9th tergum and sternum broken from specimen; see figure for conformation of 8 th sternum and bursal cavity.

Male unknown.

KELSEY, L. P.

REFERENCES

1969. A Revision of the Scenopinidae (Diptera) of the World. U.S. Nat. Museum, Bull. 277: 1-336, 208 figures. 


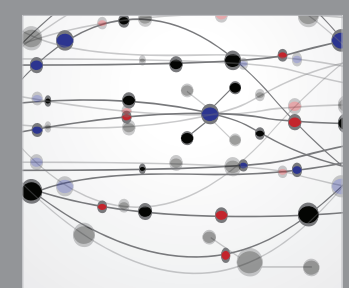

The Scientific World Journal
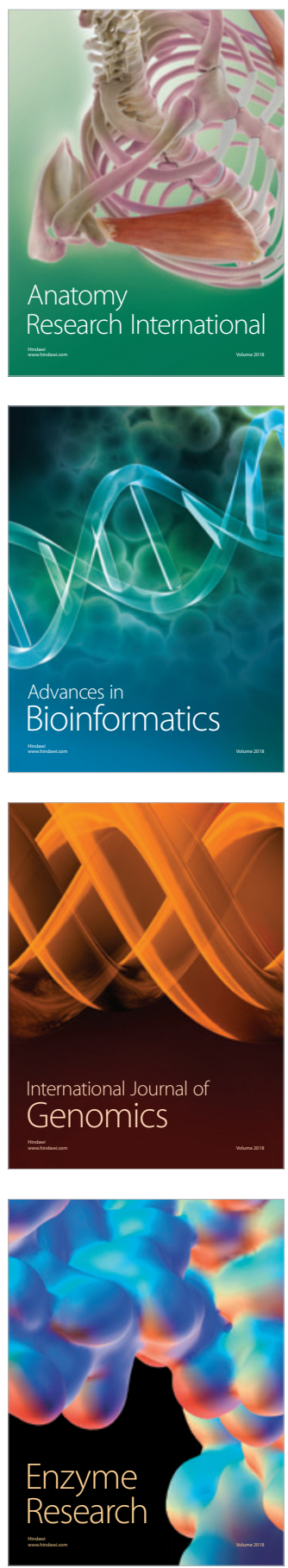
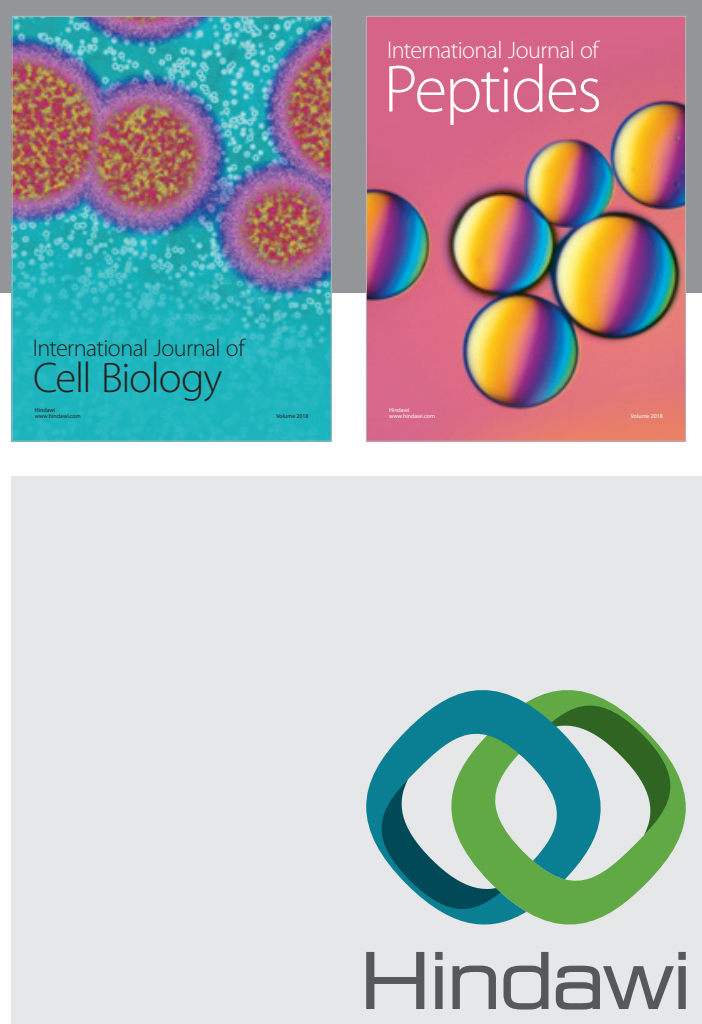

Submit your manuscripts at

www.hindawi.com
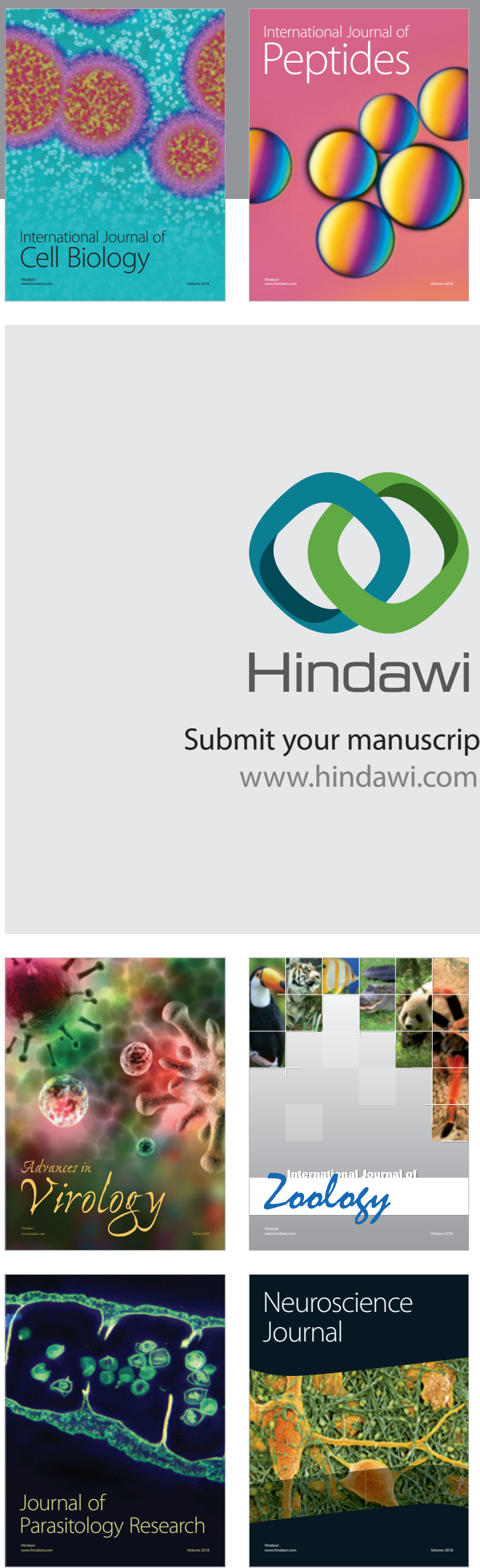
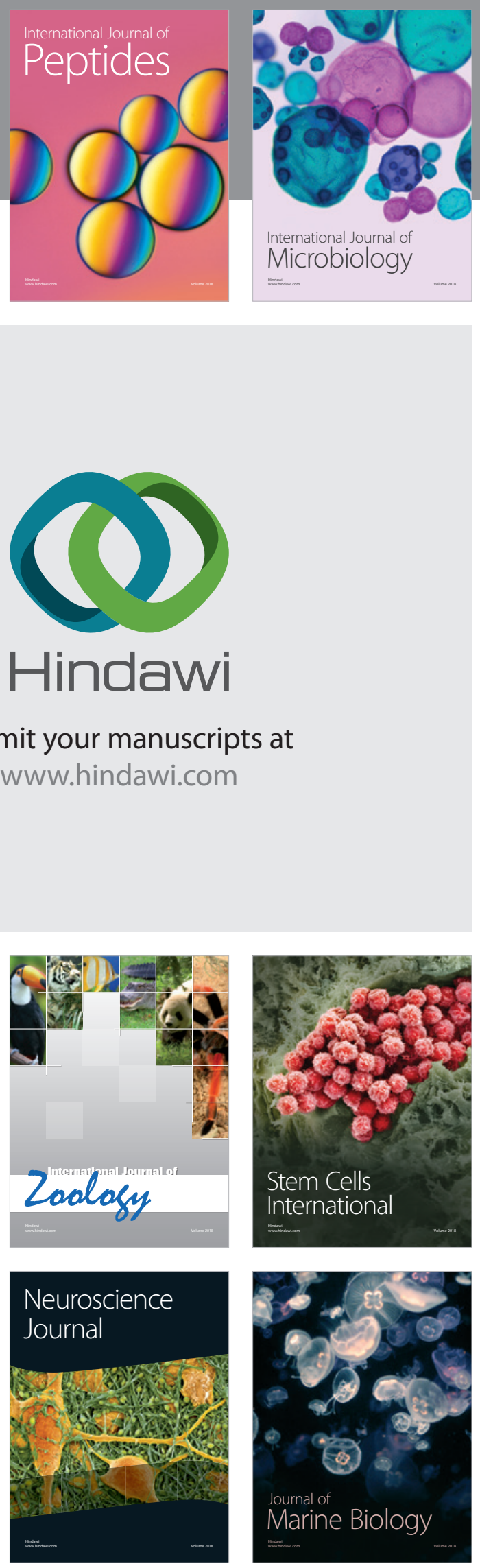
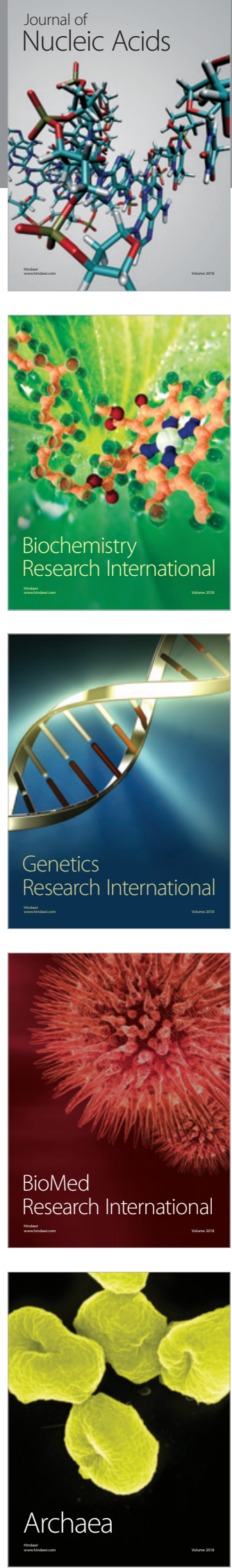